\title{
SCIDiC
}

\author{
International Journal of Dentistry and Oral Science (IJDOS) \\ ISSN: 2377-8075
}

\section{Effect Of Intracanal Medicaments On RANKL and OPG Levels}

Research Article

Keerthana ${ }^{1}$, Lakshmi Thangavelu ${ }^{1 *}$

${ }^{1}$ Department of Pharmacology, Saveetha Dental College and Hospitals, Saveetha Institute of Medical and Technical Sciences, Saveetha University, Chennai, India.

\section{Abstract}

The application of antimicrobial intracanal medication is recommended to remove bacteria that could not be removed from the root canal system after instrumentation and irrigation of the root canals. The aim of the present study was to evaluate the effects of calcium hydroxide alone and calcium hydroxide in combination with ibuprofen and ciprofloxacin on RANKL and OPG levels in periapical lesions cases. Thirty single rooted teeth with periapical lesions which require root canal treatment were randomly divided in to 2 groups; Group I- calcium hydroxide and Group II- calcium hydroxide with combination of ibuprofen and ciprofloxacin. After access opening and working length determination, interstitial fluid of the apical tissues was collected using paper points to assess the RANKL and OPG levels. Following which cleaning and shaping of the root canals were done and intracanal dressing was given (Group I $n=15$, Group II $n=15$ ). In the second appointment, medicaments were removed, and second sampling was performed using the same method. The RANKL and OPG levels were measured by the enzyme-linked immunosorbent assay, and the RANKL/OPG ratio was calculated. RANKL and OPG levels in pretreatment were Group I $-0.75 \mathrm{pg} / \mathrm{ml}$ and $0.22 \mathrm{pg} / \mathrm{ml}$ and for Group II it was $0.72 \mathrm{pg} / \mathrm{ml}$ and $0.2 \mathrm{pg} / \mathrm{ml}$ respectively. Post treatment RANKL and OPG were in group I $0.55 \mathrm{pg} / \mathrm{ml}$ and $0.67 \mathrm{pg} / \mathrm{ml}$ and in group II it was 0.48 and $0.34 \mathrm{pg} / \mathrm{ml}$ respectively. There was a significant difference between the groups in RANKL/OPG ratio, post treatment which showed RANKL and OPG ratio in the post treatment was less in Group I (0.8) compared with Group II $(1.40)(p=0.02)(p<0.05)$. With in the limitations of the study it proved that addition of ibuprofen and ciprofloxacin to calcium hydroxide did not have any extra benefit in lowering the RANKL/OPG ratio in periapical lesion cases.

Keywords: Intracanal Medicament; Calcium Hydroxide; Ciprofloxacin; RANKL; OPG.

\section{Introduction}

Bacterial infection of the dental pulp results in pulpal destruction, and subsequently stimulates an inflammatory cell response and destruction of bone in the periapex. Bacterial components, including lipopolysaccharides, induce the production of many polypeptide mediators, or cytokines, by inflammatory cells. These cytokines, which include macrophage-derived interleukin-1 beta, interleukin-1 alpha and tumor necrosis factor, and lymphocytederived lymphotoxin, have been shown to potently stimulate bone resorption and to inhibit reparative bone formation in vitro and in vivo [1]. The most common species recovered in over one-third of the root canal teeth with persisting periapical lesion is the Enterococcus faecalis (E. Faecalis). Enterococcus faecalis is a grampositive, facultative anaerobic, coccoid bacteria. Medicaments are recommended to eliminate remaining microbes in the root canal, dentinal tubules, accessory canals, canal irregularities and in the periapical/periodontal tissue to reduce periapical inflammation, encourage periapical healing and control inflammatory bone resorption [2].

Calcium hydroxide exerts antibacterial effects in the root canal system as long as a high $\mathrm{pH}$ is maintained. It was shown that a 7-day application of a calcium hydroxide medicament was sufficient to reduce canal bacteria to a level that gave a negative culture [3]. It has also been shown that an aqueous calcium hydroxide paste and a silicone oil-based calcium hydroxide paste are effective in the elimination of enterococcus faecalis in dentinal tubules [4].

\footnotetext{
*Corresponding Author:

Lakshmi Thangavelu,

Department of Pharmacology, Saveetha Dental College and Hospitals, Saveetha Institute of Medical and Technical Sciences, Saveetha University, Chennai, India.

Email Id: Lakshmi@saveetha.com
}

Received: February 25, 202

Accepted: March 04, 2021

Published: March 19, 2021

Citation: Keerthana, Lakshmi Thangavelu. Effect Of Intracanal Medicaments On RANKL and OPG Levels. Int J Dentistry Oral Sci. 2021;08(03):2041-2044. doi: http://dx.doi org/10.19070/2377-8075-21000401

Copyright: Lakshmi Thangavelu ${ }^{\circ} 2021$. This is an open-access article distributed under the terms of the Creative Commons Attribution License, which permits unrestricted use, distribution and reproduction in any medium, provided the original author and source are credited. 
Non-steroidal antiinflammatory drugs (NSAIDs) are commonly used medicines for the management of pain and inflammation in dentistry. Studies have demonstrated that some NSAIDs have antibacterial action [5]. This property has been more extensively studied about ibuprofen in comparison with other NSAIDs. Ibuprofen is a potent anti inflammatory, analgesic and antipyretic agent with less gastrointestinal side effects. Intracanal or systemic application of ibuprofen has also shown to reduce post-operative endodontic pain [6]. Ibuprofen has exhibited profound antibacterial effects against both gram-positive and gram-negative bacteria. It has also shown synergism with other antibiotics [7].

Ciprofloxacin has antimicrobial activity against most Gram-negative bacilli and cocci. The usage of local antibiotics in endodontic treatment was advocated by Grossman in 1951. Since then numerous antibiotics have been used during endodontic treatment. Local application of ciprofloxacin like intracanal medicament in endodontics enhances many positive prospects, including a complete or near-complete bacterial elimination, and higher local drug concentrations in addition to minimizing systemic adverse effects. The antibiotic combination has proved advantageous with the usage of triantibiotic paste [8].

There has been only one in vitro study comparing calcium hydroxide combined with ciprofloxacin or ibuprofen in terms of antimicrobial action and $\mathrm{pH}$ changes [9]. Currently, one of the concerns in endodontics is the treatment of teeth with necrotic pulps and periapical pathosis, because treatment failure is higher than in cases without periapical disease [10]. In teeth with chronic periapical lesions, there is a greater prevalence of gram-negative anaerobic bacteria disseminated throughout the root canal system, including apical bacterial biofilm [11]. Because these areas are not reached by instrumentation, the use of a root canal medicament is recommended to aid in the elimination of these bacteria and to increase the possibility of clinical success [12]. Teeth with and without radiographically visible periapical disease could be considered as different pathological entities requiring different treatment regimens. Where bone loss has occurred, the use of a root canal medicaments not between treatment sessions is recommended by some, because the success of treatment in cases with periapical pathosis is directly related to the elimination of bacteria from the root canal system. The procedures and medications used in root canal treatment should lead not only to bacterial death but also to the inactivation of bacterial endotoxin [13].

We have numerous highly cited publications on well designed clinical trials and lab studies [14-29]. This has provided the right platforms for us to pursue the current study. Our aim of the present study was to evaluate the effects of calcium hydroxide and calcium hydroxide in combination with ibuprofen and ciprofloxacin affects the RANKL and OPG levels which in turn influences the bone resorption in periapical lesions cases.

\section{Materials and Method}

\section{Patient Selection:}

Total of 30 patients who underwent root canal treatment with periapical lesions were taken in the study. The study protocol received institutional approval from the Ethics Committee of the university. The study group consisted of patients aged between
25-60 years undergoing root canal treatment with periapical lesions for single rooted teeth. Exclusion criteria includes medically compromised patients, pregnancy, steroid therapy, metabolic disorder patients. All the patients who were included in the study were informed about the treatment procedure and possible complications were also explained to them. Informed consent was taken from them.

\section{Specimen Preparation:}

Teeth were isolated and disinfected using 30\% $\mathrm{H} 2 \mathrm{O} 2 \mathrm{v} / \mathrm{v}$ and $2.5 \% \mathrm{NaOCl}$ for $30 \mathrm{sec}$ then $5 \%$.

sodium thiosulphate was used to inactivate the $2.5 \% \mathrm{NaoCl}$. During instrumentation the root canals were irrigated with $2 \mathrm{ml} 1 \%$ $\mathrm{NaOCl}$. The canals were then irrigated again with distilled water for $1 \mathrm{~min}$ after root canal instrumentation. To obtain the test samples, 3 sterile paper points were placed in to the root canals beyond $2 \mathrm{~mm}$ root apex and were kept in position for $60 \mathrm{sec}$. Thereafter the paper points were cut $4 \mathrm{~mm}$ from the tip. Samples were stored in sterile tubes that contain PBS at $-80^{\circ} \mathrm{C}$.

\section{Preparation Of Chemicals:}

The study consists of two groups

\section{Group 1: Treatment with Calcium hydroxide paste;}

Group 2: Treatment with Calcium hydroxide + Ibuprofen + Ciprofloxacin.

Group 1: 5mg of Calcium hydroxide powder was dissolved in $1 \mathrm{ml}$ of sterile water.

Group II: $95 \mathrm{mg}$ of Calcium hydroxide powder mixed with $2.5 \mathrm{mg}$ of Ibuprofen and $2.5 \mathrm{mg}$ ciprofloxacin in $1 \mathrm{ml}$ of sterile water.

The medicaments were placed in the root canal and access cavity closed with temporary filling.

Three days later the root canals medication was removed and cleaned with $17 \%$ EDTA and then with distilled water. The interstitial fluid was collected from the apical tissue through the paper points that were used to dry the root canal and stored at $-80^{\circ} \mathrm{C}$. The RANKL and OPG ELISA kit was purchased from Elab biosciences commercial kit.

\section{Estimation RANKL:}

Pipetted out $100 \mu \mathrm{l}$ of standards and test samples in to the appropriate wells and incubated the plate at room temperature for 1 hour, centrifuge at $300 \mathrm{rpm}$ and then washed the wells. Added $100 \mu$ l of Biotin Labelled Antibody into each well. Incubated the plate at room temperature $25^{\circ} \mathrm{C}$ for 1 hour, centrifuge at $300 \mathrm{rpm}$ on an orbital microplate shaker. Added $100 \mu$ of StreptavidinHRP Conjugate into each well. After washing, $100 \mu$ l of substrate Solution was added into each well. The incubation time may be extended up to 20 minute if the reaction temperature is below $20^{\circ} \mathrm{C}$. Absorbance was read within 5 minutes using a microplate reader set to $450 \mathrm{~nm}$.

\section{Estimation Of OPG:}


About $100 \mu$ lof antibody was coated on a microtiter plate and incubated overnight Then, $100 \mu \mathrm{L}$ of diluted sample and standards were added to appropriate wells and covered with adhesive strips followed by incubation for two hours at room temperature. Later, $100 \mu \mathrm{L}$ (each) of working dilution of streptavidin-horseradish peroxidase (HRP) and substrate solution were added to each well, after washing the plate three times with wash buffer between each addition, and incubated for 20 minutes at room temperature. Finally, $50 \mu \mathrm{L}$ of stop solution was added to each well to stop enzyme reaction and the color generated was read at $450 \mathrm{~nm}$. The concentration of OPG in the tested samples was calculated using the standard curve plotted using the optical density values with the standards.

The data was collected and subjected to statistical analysis using independent $t$ test and the significance level was set at 0.05 .

\section{Results and Discussion}

RANKL and OPG levels in pretreatment were Group I - 0.75pg/ $\mathrm{ml}$ and $0.22 \mathrm{pg} / \mathrm{ml}$ and for Group II it was $0.72 \mathrm{pg} / \mathrm{ml}$ and 0.2 $\mathrm{pg} / \mathrm{ml}$ respectively. Post treatment RANKL and OPG were in group I $0.55 \mathrm{pg} / \mathrm{ml}$ and $0.67 \mathrm{pg} / \mathrm{ml}$ and in group II it was 0.48 and $0.34 \mathrm{pg} / \mathrm{ml}$ respectively. Following placement of intracanal medicament, in Group I, RANKL $<$ OPG showing a haemostatic condition. in Group II RANKL > OPG showing an inflammatory condition. RANKL and OPG ratio of Group I $(0.8 \mathrm{pg} / \mathrm{ml})$ was lesser than Group II $(1.4 \mathrm{pg} / \mathrm{ml})$ [Table 1] There was a significant difference between the groups in RANKL/OPG ratio, post treatment which showed RANKL and OPG ratio in the post treatment was less in Group I (0.8) compared with Group II (1.40) $(p=0.02),(p<0.05)$ [Figure 1].
According to the results of our study, there were no statistically significant differences among the groups in terms of pre and post treatment levels of RANKL/OPG. With in the groups there was a significant difference in the RANKL/OPG ratio in group II and decrease in the group I, post treatment.

Bone resorption is regulated by the interaction between RANKL and OPG-31,32. Although RANKL controls the activation and maturation of pre osteoblasts via the interaction between RANKL and its receptor RANK on the preosteoclast surface, OPG, which is a decoy receptor for RANKL, prevents the interaction between RANK and RANKL. RANKL produced by osteoblast lineage cells and activated T lymphocytes is the essential factor for osteoclast formation, fusion, activation, and survival, thus resulting in bone resorption and bone loss. The effects of RANKL are counteracted by OPG which acts as a soluble neutralizing receptor. RANKL and OPG are regulated by various hormones, cytokines, and various mesenchymal transcription factors. The discovery and characterization of RANKL, RANK, and OPG, have led to a detailed understanding of bone resorption in periapical lesions and may form the basis of innovative therapeutic strategies [30].

Root canal treatment usually results in complete healing of periapical lesions. However, according to the results of the present study, there was no statistically significant difference between the pre- and post treatment RANKL/OPG ratio. This could be explained by the amount of apically extruded debris, instrumentation which may lead to the deterioration of periapical healing [31].

A previous cell culture study conducted by Deepak et al evaluated the effect of calcium hydroxide on the level of RANKL/OPG and concluded that there was a statistically significant difference between the control and calcium hydroxide treatment [32]. This is

Table 1. Table represents the RANKL and OPG levels of both the groups, pre and post treatment. In pre-treatment,

RANKL > OPG in Group I as well as Group II. Post treatment it was found that RANKL $<$ OPG in Group I and in Group II RANKL<OPG. RANKL/OPG ratios post treatment was $0.8 \mathrm{pg} / \mathrm{ml}$ in group I and $1.4 \mathrm{pg} / \mathrm{ml}$ in group II.

\begin{tabular}{|c|c|c|c|c|}
\hline & \multicolumn{2}{|c|}{ Pre Treatment (mean) } & \multicolumn{2}{c|}{ Post Treatment (mean) } \\
\hline Parameters & Group I & Group II & Group I & Group II \\
\hline RANKL $(\mathrm{pg} / \mathrm{ml})$ & 0.75 & 0.72 & 0.55 & 0.48 \\
\hline OPG $(\mathrm{pg} / \mathrm{ml})$ & 0.22 & 0.2 & 0.67 & 0.34 \\
\hline RANKL/OPG & 3.4 & 3.6 & 0.8 & 1.4 \\
\hline
\end{tabular}

Figure 1. Bar chart represents the RANKL and OPG ratio of both the groups in pre and post treatment. $\mathrm{X}$ axis shows the RANKL and OPG ratio of two groups, pre and post treatment. $Y$ axis shows the mean of RANKL and OPG. It is found that the RANKL and OPG ratio in the post treatment was less in Group I (blue) (0.8) compared with Group II (red) (1.40). $(\mathrm{p}=0.002), \mathrm{p}<0.05$, statistically significant.

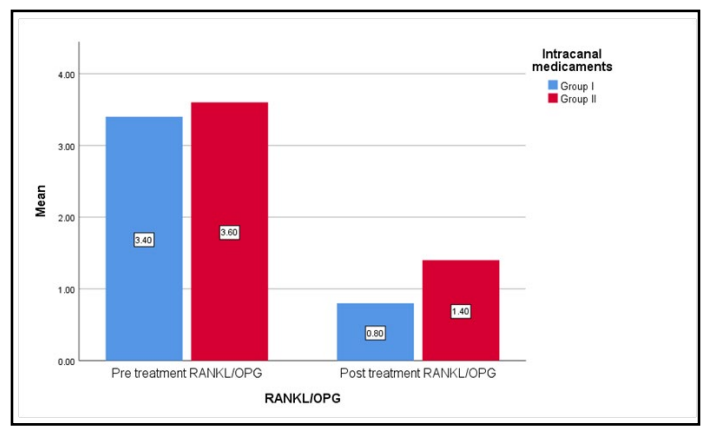


in accordance with the results of our present study. It was found that on addition of ibuprofen and antibiotic increased the OPG levels. This is due to the PGE 2 expression in the NSAID evoked the interleuk in which ultimately increased the OPG levels. According to Fretias et al, it was found that the combination of an antibiotic and NSAID did not change the $\mathrm{pH}$ of the calcium hydroxide paste and enhanced the antimicrobial action against enterococcus faecalis biofilm formation [9].

The limitations of the study was small sample size and the amount of the additives added to calcium hydroxide were way lesser than the calcium hydroxide. Thus future studies can be conducted with a larger sample size and to investigate the effect of different additives on RANKL and OPG.

\section{Conclusion}

With in the limitations of the present study it was found that the OPG levels were increased in Group I and decreased in Group II thus proving that calcium hydroxide alone had better hemostatic effect on the bone resorption. However addition of ibuprofen and ciprofloxacin did not have any extra benefit in lowering the RANKL/OPG ratio. However further investigations need to be done to substantiate the findings.

\section{References}

[1]. Danin J. Factors associated with healing of periradicular lesions. Institutionen för immunologi, mikrobiologi, patologi och infektionssjukdomar/ Department of Immunology, Microbiology, Pathology and Infectious Diseases.2003 Jan 24.

[2]. Landman D, Mobarakai NK, Quale JM. Novel antibiotic regimens against Enterococcus faecium resistant to ampicillin, vancomycin, and gentamicin. Antimicrob Agents Chemother. 1993 Sep;37(9):1904-8.Pubmed PMID: 8239604.

[3]. Sjögren U, Figdor D, Spångberg L, Sundqvist G. The antimicrobial effect of calcium hydroxide as a short-term intracanal dressing. Int. Endod. J. 1991 May;24(3):119-25.

[4]. Han GY, Park SH, Yoon TC. Antimicrobial activity of $\mathrm{Ca}(\mathrm{OH}) 2$ containing pastes with Enterococcus faecalis in vitro. J Endod. 2001 May;27(5):328-32. Pubmed PMID: 11485250

[5]. Wang WH, Wong WM, Dailidiene D, Berg DE, Gu Q, Lai KC, et al. Aspirin inhibits the growth of Helicobacter pylori and enhances its susceptibility to antimicrobial agents. Gut. 2003 Apr;52(4):490-5.Pubmed PMID: 12631656

[6]. Negm MM. Effect of intracanal use of nonsteroidal anti-inflammatory agents on posttreatment endodontic pain. Oral Surg Oral Med Oral Pathol. 1994 May;77(5):507-13.Pubmed PMID: 8028874.

[7]. Dutta NK, Mazumdar K, Dastidar SG, Park JH. Activity of diclofenac used alone and in combination with streptomycin against Mycobacterium tuberculosis in mice. Int J Antimicrob Agents. 2007 Oct;30(4):336-40.Pubmed PMID: 17644321

[8]. Asif M. The fluoroquinolones as antibacterial compounds; an overview on biological and chemical activities aspects. J. Curr. Pharm.Res. 2016 Jul $1 ; 6(4): 1912-29$.

[9]. Freitas RP de, de Freitas RP, Greatti VR, et al. Effect of the Association of Nonsteroidal Anti-inflammatory and Antibiotic Drugs on Antibiofilm Activity and $\mathrm{pH}$ of Calcium Hydroxide Pastes. Journal of Endodontics 2017; 43: $131-134$.

[10]. Leonardo MR, da Silva LA, Leonardo Rde T, Utrilla LS, Assed S. Histological evaluation of therapy using a calcium hydroxide dressing for teeth with incompletely formed apices and periapical lesions. J Endod. 1993 Jul;19(7):348-52.Pubmed PMID: 8245757.

[11]. Katebzadeh N, Hupp J, Trope M. Histological periapical repair after obturation of infected root canals in dogs. J. Endod. 1999 May 1;25(5):364-8.

[12]. Nelson-Filho P, Leonardo MR, Silva LA, Assed S. Radiographic evaluation of the effect of endotoxin (LPS) plus calcium hydroxide on apical and periapical tissues of dogs. J. Endod. 2002 Oct 1;28(10):694-6.
[13]. Safavi KE, Nichols FC. Effect of calcium hydroxide on bacterial lipopolysaccharide. J. Endod. 1993 Feb 1;19(2):76-8.

[14]. Ramarao S, Sathyanarayanan U. CRA Grid - A preliminary development and calibration of a paper-based objectivization of caries risk assessment in undergraduate dental education. J Conserv Dent. 2019 Mar-Apr;22(2):185-190. Pubmed PMID: 31142991.

[15]. Poorni S, Srinivasan MR, Nivedhitha MS. Probiotic Streptococcus strains in caries prevention: A systematic review. J Conserv Dent. 2019 Mar;22(2):123128.

[16]. Manohar MP, Sharma S. A survey of the knowledge, attitude, and awareness about the principal choice of intracanal medicaments among the general dental practitioners and nonendodontic specialists. Indian J Dent Res. 2018 Nov-Dec;29(6):716-720.Pubmed PMID: 30588997.

[17]. Azeem RA, Sureshbabu NM. Clinical performance of direct versus indirect composite restorations in posterior teeth: A systematic review. J Conserv Dent. 2018 Jan;21(1):2-9.

[18]. Jenarthanan S, Subbarao C. Comparative evaluation of the efficacy of diclofenac sodium administered using different delivery routes in the management of endodontic pain: A randomized controlled clinical trial. J Conserv Dent. 2018 May-Jun;21(3):297-301.Pubmed PMID: 29899633.

[19]. Nandakumar M, Nasim I. Comparative evaluation of grape seed and cranberry extracts in preventing enamel erosion: An optical emission spectrometric analysis. J Conserv Dent. 2018 Sep-Oct;21(5):516-520.Pubmed PMID: 30294113.

[20]. Malli Sureshbabu N, Selvarasu K, V JK, Nandakumar M, Selvam D. Concentrated Growth Factors as an Ingenious Biomaterial in Regeneration of Bony Defects after Periapical Surgery: A Report of Two Cases. Case Rep Dent. 2019 Jan 22;2019:7046203.Pubmed PMID: 30805222.

[21]. Siddique R, Nivedhitha MS, Jacob B. Quantitative analysis for detection of toxic elements in various irrigants, their combination (precipitate), and para-chloroaniline: An inductively coupled plasma mass spectrometry study. J Conserv Dent. 2019 Jul-Aug;22(4):344-350.Pubmed PMID: 31802817.

[22]. Teja KV, Ramesh S, Priya V. Regulation of matrix metalloproteinase-3 gene expression in inflammation: A molecular study. J Conserv Dent. 2018 Nov;21(6):592-596.

[23]. Rajakeerthi R, Nivedhitha MS. Natural Product as the Storage medium for an avulsed tooth-A Systematic Review. Cumhur. Dent. J. 2019;22(2):24956.

[24]. Siddique R, Nivedhitha MS. Effectiveness of rotary and reciprocating systems on microbial reduction: A systematic review. J Conserv Dent. 2019 Mar-Apr;22(2):114-122.Pubmed PMID: 31142978.

[25]. Janani K, Sandhya R. A survey on skills for cone beam computed tomography interpretation among endodontists for endodontic treatment procedure. Indian J Dent Res. 2019 Nov-Dec;30(6):834-838.Pubmed PMID: 31939356.

[26]. Siddique R, Sureshbabu NM, Somasundaram J, Jacob B, Selvam D. Qualitative and quantitative analysis of precipitate formation following interaction of chlorhexidine with sodium hypochlorite, neem, and tulsi. J Conserv Dent. 2019 Jan-Feb;22(1):40-47.Pubmed PMID: 30820081.

[27]. Rajendran R, Kunjusankaran RN, Sandhya R, Anilkumar A, Santhosh R, Patil SR. Comparative evaluation of remineralizing potential of a paste containing bioactive glass and a topical cream containing casein phosphopeptide-amorphous calcium phosphate: An in vitro study. Pesqui. Bras. Odontopediatria Clín. Integr. 2019;19:1-10.

[28]. Govindaraju L, Neelakantan P, Gutmann JL. Effect of root canal irrigating solutions on the compressive strength of tricalcium silicate cements. Clin Oral Investig. 2017 Mar;21(2):567-571.Pubmed PMID: 27469101.

[29]. Khandelwal A, Palanivelu A. Correlation between dental caries and salivary albumin in adult population in Chennai: An in vivo study. Braz. Dent. Sci. 2019 Apr 30;22(2):228-33.

[30]. Khonsuphap P, Pavasant P, Irwandi RA, Leethanakul C, Vacharaksa A. Epithelial Cells Secrete Interferon-y Which Suppresses Expression of Receptor Activator of Nuclear Factor Kappa-B Ligand in Human Mandibular Osteoblast-Like Cells. J Periodontol. 2017 Mar;88(3):e65-e74.Pubmed PMID: 27762732.

[31]. Gusiyska A, Gateva N, Kabaktchieva R, Stanimirov P, Raychev I. Retrospective study of the healing processes of endodontically treated teeth characterized by osteolytic defects of the periapical area: four-year follow-up. Biotechnol. Biotechnol. Equip. 2017 Jan 2;31(1):187-92.

[32]. Chockattu SJ, Deepak BS, Goud KM. Comparison of efficiency of ethylenediaminetetraacetic acid, citric acid, and etidronate in the removal of calcium hydroxide intracanal medicament using scanning electron microscopic analysis: An in-vitro study. J Conserv Dent. 2017 Jan-Feb;20(1):6-11.Pubmed PMID: 28761245. 